\title{
Distribution of meticillin-resistant Staphylococcus aureus spa types isolated from health-care workers and patients in a Scottish university teaching hospital
}

\author{
Correspondence \\ David H. Edwards \\ d.h.edwards@dundee.ac.uk
}

Received 2 March 2009

Accepted 2 June 2009

\author{
Reham S. Soliman, ${ }^{1}$ Gabby Phillips, ${ }^{1}$ Patrick Whitty ${ }^{2}$ \\ and David H. Edwards ${ }^{2}$ \\ ${ }^{1}$ Department of Medical Microbiology, Ninewells Hospital, Dundee DD1 9SY, UK
${ }^{2}$ Clinical Dental Sciences, Dundee Dental School, University of Dundee, Park Place, Dundee DD1
4HN, UK
}

\begin{abstract}
Our study was aimed at comparing the meticillin-resistant Staphylococcus aureus (MRSA) strains isolated from an anonymous group of health-care workers (HCWs) with those obtained from patient samples during a 3-month time interval. We employed spa typing and virulence gene profiling to characterize the MRSA strains. Our data revealed that a total of 14 discrete spa types were circulating in both patients and HCWs. The t032 spa type, characteristic of EMRSA15 and the Barnim EMRSA ST 22 clones, accounted for over $70 \%$ of isolates, and was equally distributed between patients and HCW groups. In addition, a number of epidemic and sporadic strains were identified, which highlighted the diversity of spa types that can be found within a health-care setting. Virulence profiling for the carriage of 7 genes by the 14 different spa types demonstrated that 10 types carried the $f n b A, c n a, s d r E, h / g$ and ica virulence factors. We concluded that there was no significant difference between the MRSA strains found circulating in the patients and the HCWs, and noted that the dominant spa types carried an identical set of virulence genes that included the key adhesins $f n b A$, cna and $s d r E$.
\end{abstract}

\section{INTRODUCTION}

Staphylococcus aureus is an important human pathogen and is one of the most significant causes of health-careassociated infections in the UK. In an attempt to control the high mortality and morbidity of systemic meticillinresistant S. aureus (MRSA) infections, techniques have been developed to analyse the genetic relatedness of different strains and help inform infection control policies. The single most important identification method is PFGE; however, the complexity, cost and lack of inter-laboratory standardization have led to the appearance of alternative methods (Deurenberg et al., 2007). For long-term global studies on the evolution of strains, multilocus sequence typing is the most commonly used technique (Enright \& Spratt, 1999), while for short-term studies on molecular evolution and nosocomial outbreaks, spa typing has proved an excellent tool (Koreen et al., 2004; Malachowa et al., 2005; Shopsin et al., 1999).

Alongside the development of sequenced-based typing methods, attention has become focused on the comparison

Abbreviations: CA-MRSA, community-acquired MRSA; HCW, healthcare worker; MRSA, meticillin-resistant Staphylococcus aureus; SMRSA, sporadic MRSA. of different MRSA genomes. In particular, the number of studies on the distribution of genes that are directly involved in causing disease has increased (Kuhn et al., 2006; Nashev et al., 2004; Peacock et al., 2002). These genes encode a variety of products that are referred to as virulence factors. Examples include PVL, a toxin linked to the occurrence of necrotizing pneumonia (Brown et al., 2009; Labandeira-Rey et al., 2007); ETA, the toxin responsible for scalded skin syndrome (Amagai et al., 2000); and CNA, the collagen-binding protein that is associated with osteomyelitis (Elasri et al., 2002). In 2002, Peacock et al. (2002) compared the distribution of 33 putative virulence factors amongst $S$. aureus strains isolated from the nasal passages of blood donors and strains responsible for invasive disease. This work suggested that seven specific virulence factors were over-represented in invasive isolates.

Our study aimed at characterizing the MRSA strains carried transiently by health-care workers (HCWs), and comparing them with invasive and non-invasive strains isolated from patients. The 87 samples were collected over a 3-month period in the autumn of 2004 and were typed by spa sequencing. This analysis identified 14 different spa types, with one class, t032, accounting for over $70 \%$ of all 
our MRSA strains. We also screened 14 individual isolates representing each distinct spa type for the carriage of the 7 virulence factors identified by Peacock et al. (2002). This work showed that two of the most common virulence factor profiles found in the original study could be assigned to 12 of the 14 spa types identified in our samples.

\section{METHODS}

Screening and sample acquisition. The 87 MRSA strains analysed in this study were isolated from staff and patients associated with a Scottish teaching hospital. The largest single group of isolates $(n=46)$ was obtained from an anonymous study analysing transient MRSA nasal colonization in $512 \mathrm{HCWs}$, which included staff who worked in wards where MRSA was considered to be either endemic or sporadic. The study was performed over 3 months, and to ensure anonymity, positive results were not followed up to investigate clearance. To compare the MRSA strains recovered from the HCWs with those found in the in-patients, we used two additional groups of samples obtained during the same period of time. The first group consisted of 20 MRSA strains that were isolated from the same wards during the routine analysis of nasal, perineal and axillary swabs obtained from in-patients sampled within $24 \mathrm{~h}$ of hospital admission. These patients had no previous history of deep-seated MRSA infection. The second group consisted of 21 MRSA isolates from blood culture. Each of these isolates was obtained from an individual subject, with no repeat isolates included. In addition, 19 of these blood cultures had previously been typed by PFGE at the Scottish Reference Laboratory, and consequently their identification by spa typing could be cross-referenced with the original results.

Identification and purification of chromosomal DNA. All the MRSA isolates were recovered from $-70{ }^{\circ} \mathrm{C}$ storage on Protech beads (Technical Services Consultants). The strains were streaked on blood agar and inoculated into $2 \mathrm{ml}$ Luria broth for incubation overnight at $37^{\circ} \mathrm{C}$. Prior to DNA extraction, the live cultures were heatinactivated by incubating at $70{ }^{\circ} \mathrm{C}$ for $30 \mathrm{~min}$. The cells from each sample were then harvested by centrifugation and the pellet was resuspended in $180 \mu \mathrm{l}$ enzymic lysis buffer supplemented with $10 \mu \mathrm{l}$

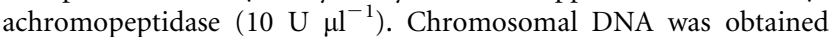
using the DNeasy Tissue kit (Qiagen) protocol and the chromosomal DNA was eluted in a final volume of $400 \mu \mathrm{l} \mathrm{dH}_{2} \mathrm{O}$.

PCR and DNA sequence analysis. To obtain the strain data for our study, we chose to employ spa typing, a DNA sequence-based method that has proved valuable in several epidemiological investigations (Frenay et al., 1996; Harmsen et al., 2005; Koreen et al., 2004). This technique has been developed as a universal approach for MRSA typing that allows inter-laboratory exchange of information via a standard software analysis package and central internet depository (www.ridom.de) (Frenay et al., 1996; Harmsen et al., 2003). For typing of the polymorphic region of protein $\mathrm{A}$, the $\mathrm{x}$ region of the $s p a$ gene was amplified using primers $1113 \mathrm{~F}$ and 1514R (CAGCAGTAGTGCCGTTTGCTT) as described previously (Harmsen et al., 2003). The PCR products were purified using the ChargeSwitch PCR Clean-Up kit (Invitrogen) and the resulting DNA fragments were quantified by gel electrophoresis. Bidirectional DNA sequences were obtained using an ABI 3730 Genetic Analyzer and data were analysed using the Ridom StaphType software (Harmsen et al., 2003). The Ridom software assigns a reliability score to the sequence data and places the data into one of 10 categories. For this study, we chose to use only data that the software considered to be either 'very good' or 'excellent', and therefore repeated the PCR amplification and sequence analysis of 7 spa products. To check the accuracy of our data, we compared our results with PFGE information generated by the Scottish MRSA Reference Laboratory as either part of their routine surveillance of blood cultures $(n=19)$, or, in the case of 10 isolates, as a special request. In total, we compared PFGE and spa identification for 29 of our 87 isolates and the correlation with the Reference Laboratory results indicated that our spa typing was reliable. Data clustering of individual spa types into clonal complexes was achieved using the Based Upon Repeat Pattern (BURP) algorithm set at a cost setting of 4 .

For the virulence gene profiling of individual spa types for the presence or absence of the $c n a, s d r E$, sej, eta, $h l g$ and ica genes, we used the PCR amplification procedure described by Peacock et al. (2002). To distinguish between the presence of the $f n b A$ and $f n b B$ genes, we performed in silico PCR analysis using the published $S$. aureus genomes and several primer sets described in the literature (Kuhn et al., 2006; Nashev et al., 2004; Peacock et al., 2002). Subsequently we chose to use the primers fnbAf and fnbAr (Kuhn et al., 2006). PCR detection of the lukF gene, which encodes the potent leukotoxin PVL, was performed as described previously (Lina et al., 1999). For each set of PCRs, we included one reaction using chromosomal DNA from a positive control strain. The presence or absence of a particular virulence factor was then confirmed by gel electrophoresis and the identification of the correct sized DNA product.

PFGE and antimicrobial susceptibility testing. The PFGE identification and antimicrobial susceptibility testing of the 14 distinct spa types was performed by the Scottish MRSA Reference Laboratory. PFGE typing of SmaI (Gibco-BRL)-digested DNA was performed as described previously (Bannerman et al., 1995; MacKenzie et al., 2002), with MRSA identities assigned by comparison with in-house standards. The antimicrobial screening for penicillin, meticillin, cefoxitin, erythromycin, clindamycin, ciprofloxacin, tetracycline, gentamicin, fusidic acid, kanamycin, mupirocin, chloramphenicol, trimethoprim, rifampicin, tobramycin and linezolid was also performed at the Reference Laboratory.

\section{RESULTS AND DISCUSSION}

\section{Molecular typing}

Typing and analysis of MRSA strains responsible for serious infections is now routine in many parts of the world, including Scotland. Uniquely our study compared the MRSA strains transiently colonizing HCWs with MRSA strains circulating within a control group of patient samples. For the 87 isolates that we examined ( $n=46$ HCWs, $n=20$ in-patient screening, $n=21$ blood cultures), we identified 14 different spa types that, according to BURP (Harmsen et al., 2003) analysis, clustered into five distinct groups (Table 1).

Overall, the largest individual group of spa types (79/87) belonged to the EMRSA15 complex, with one spa type, t032, predominating (61/87). This was consistent with the fact that EMRSA15 is the main cause of bacteraemias within the hospital, accounting for approximately $80 \%$ of the blood cultures typed at the Scottish MRSA Reference Laboratory, and is the dominant clone within the UK (Johnson et al., 2001; Murchan et al., 2004). Similarly, the prevalence of $\mathrm{t} 032$ was predictable as this is the second most common spa type deposited on the Spa Server, accounting for $9.83 \%$ of all the isolates, and is widely disseminated throughout Europe (Ghebremedhin et al., 2007; Moore \& Lindsay, 2002; Murchan et al., 2004). The 
Table 1. Frequency of individual spa types

\begin{tabular}{|c|c|c|c|c|c|}
\hline spa type & Repeat succession & HCWs & $\begin{array}{l}\text { Patient } \\
\text { screen }\end{array}$ & $\begin{array}{l}\text { Blood } \\
\text { cultures }\end{array}$ & Total \\
\hline \multicolumn{6}{|c|}{ EMRSA15 } \\
\hline t022 & $26-23-13-23-31-29-17-31-29-17-25-17-25-16-28$ & 3 & 1 & & $4(3.5 \%)$ \\
\hline t025 & $26-23-23-13-23-29-17-31-29-17-25-17-25-16-28$ & 4 & 1 & & $5(4.5 \%)$ \\
\hline $\mathrm{t} 032$ & $26-23-23-13-23-31-29-17-31-29-17-25-17-25-16-28$ & 31 & 14 & 16 & $61(61.7 \%)$ \\
\hline $\mathrm{t} 379$ & $26-23-23-13-23-31-29-17-25-17-25-16-28$ & 1 & & & $1(0.9 \%)$ \\
\hline $\mathrm{t} 531$ & $26-23-23-13-23-31-29-17-31-29-17-25-17-16-28$ & 2 & & 1 & $3(2.6 \%)$ \\
\hline t718 & $26-23-23-23-13-23-31-29-17-31-29-17-25-17-25-16-28$ & 1 & & & $1(0.9 \%)$ \\
\hline t756 & $26-23-13-23-29-17-31-29-17-25-17-25-16-28$ & & 1 & & $1(0.9 \%)$ \\
\hline $\mathrm{t} 1302$ & $26-23-23-29-17-31-29-17-25-17-25-16-28$ & 1 & & 1 & $2(1.7 \%)$ \\
\hline txAA & $26-23-29-17-25-16-28$ & & & 1 & $1(0.9 \%)$ \\
\hline \multicolumn{6}{|c|}{ EMRSA16 } \\
\hline t012 & $15-12-16-02-16-02-25-17-24-24$ & 2 & 2 & & $4(3.5 \%)$ \\
\hline t018 & $15-12-16-02-16-02-25-17-24-24-24$ & 1 & & & $1(0.9 \%)$ \\
\hline \multicolumn{6}{|l|}{ EMRSA3 } \\
\hline t001 & $26-30-17-34-17-20-17-12-17-16$ & & 1 & & $1(0.9 \%)$ \\
\hline \multicolumn{6}{|c|}{ CA-MRSA } \\
\hline t044 & $07-23-12-34-34-33-34$ & & & 1 & $1(0.9 \%)$ \\
\hline \multicolumn{6}{|l|}{ SMRSA } \\
\hline t3209 & $04-34-24-34-22-25$ & & & 1 & $1(0.9 \%)$ \\
\hline
\end{tabular}

PFGE analysis of 14 of our 61 t032 samples confirmed their identification (Table 2), and indicated the presence of four distinct PFGE band variants within one spa class (data not shown).

The other spa types that clustered with $\mathrm{t} 032$, with the exception of t022, have not been deposited on the spa server in large numbers $(>87)$. Indeed, three of the repeat patterns in the cluster had only been reported once or twice, and txAA represented a new spa type. Although truncated, txAA included the N-terminal 26-23 motif and C-terminal 17-25-16-28 motif that is common to all but one of the other EMRSA15 spa types identified in our study. The prediction that this totally novel spa type (txAA) was related to EMRSA15 was subsequently confirmed by a PFGE pattern (15a) that matched to our t025, t718, t756 isolates and several of our t032 strains.

A second cluster, containing five isolates, was identified by the BURP algorithm. This cluster consisted of the t012 and the $\mathrm{t} 018$ repeat patterns that are characteristic of EMRSA16. This identification was confirmed for all five samples by PFGE. The three remaining isolates belonged to individual spa types. The first of these, t001, is characteristic of EMRSA3. EMRSA3 is now considered to be a relatively infrequent cause of invasive disease in Scotland, and in our case, the single isolate was obtained during the routine screening of in-patients. The second individual isolate was identified as $\mathrm{t} 044$, a spa type that characterizes a widely disseminated PVL-positive community-acquired (CA-MRSA) MRSA found throughout Europe. Consistent with this, the corresponding PFGE identity was PF118a/d, a band pattern that is associated in Scotland with the ST80 European CA-MRSA. The third individual spa type encoded six repeats (04-34-24-34-22-25) and represented a rare spa type, t3209. PFGE of our isolate established it as having a band pattern associated with a particular MRSA strain recognized in Tayside, but rarely seen elsewhere in Scotland. The PFGE data also suggested that it may be closely related to the more common sporadic strain SMRSA108 (D. Morrison, pers. comm.).

\section{Distribution of individual spa types}

Our anonymous screen of HCWs revealed no clear difference in the carriage rate associated with staff attending wards where MRSA is considered to be either endemic or sporadic (data not shown). Crucially, a similar distribution of the dominant strain was found in all three sample groups, with spa type t032 accounting for $67 \%(31 / 46)$ of the HCWs isolates, $70 \%(14 / 20)$ of the strains obtained during inpatient screening, and $76 \%(16 / 21)$ of MRSA samples responsible for invasive disease. Statistical analysis confirmed this view (chi-square test; $P$-value $=0.826$ ). Besides the EMRSA15 cluster, we identified two spa types associated with EMRSA16 $(n=5)$ and one associated with EMRSA3 $(n=1)$. None of these samples were associated with invasive disease. Our results also revealed the presence of a number of rare $s p a$ types $(\mathrm{t} 531 n=3, \mathrm{t} 756 n=1, \mathrm{t} 1302 n=2$, txAA $n=1$, t3209 $n=1$ ) and therefore indicated that a variety of MRSA strains are circulating within a hospital environment sampled over a 3-month period.

\section{Virulence profiling}

In 2002, Peacock et al. (2002) investigated the distribution of virulence factors in MRSA samples isolated from blood 
Table 2. Virulence profiling of individual spa type

\begin{tabular}{|c|c|c|c|c|c|c|c|c|c|c|c|c|}
\hline spa type & PFGE & Antibiogram $^{\star}$ & $f n b A$ & cna & $s d r E$ & sej & eta & hlg & ica & $\begin{array}{c}\text { Peacock } \\
\text { grouping } \dagger\end{array}$ & $l u k F$ & $\begin{array}{l}\text { Total no. } \\
\text { of virulence } \\
\text { factors }\end{array}$ \\
\hline t022 & $15 c$ & Pn, Mt, Cx, Cp & - & + & + & - & - & + & + & ND & - & 4 \\
\hline t025 & $15 \mathrm{a}$ & $\mathrm{Pn}, \mathrm{Mt}, \mathrm{Cx}, \mathrm{Er}, \mathrm{Cp}$ & + & + & + & - & - & + & + & $\mathrm{D}$ & - & 5 \\
\hline $\mathrm{t} 531$ & $15 \mathrm{i}$ & $\mathrm{Pn}, \mathrm{Mt}, \mathrm{Cx}, \mathrm{Er}, \mathrm{Cp}$ & + & + & + & - & - & + & + & $\mathrm{D}$ & - & 5 \\
\hline t718 & $15 \mathrm{a}$ & Pn, Mt, Cx, Er, Cp & + & + & + & - & - & + & + & $\mathrm{D}$ & - & 5 \\
\hline $\mathrm{t} 756$ & $15 \mathrm{a}$ & $\mathrm{Pn}, \mathrm{Mt}, \mathrm{Cx}, \mathrm{Cp}$ & + & + & + & - & - & + & + & $\mathrm{D}$ & - & 5 \\
\hline $\mathrm{t} 1302$ & $15-31$ & $\mathrm{Pn}, \mathrm{Mt}, \mathrm{Cx}, \mathrm{Er}, \mathrm{Cp}$ & + & + & + & - & - & + & + & $\mathrm{D}$ & - & 5 \\
\hline txAA & $15 \mathrm{a}$ & $\mathrm{Pn}, \mathrm{Mt}, \mathrm{Cx}, \mathrm{Cp}$ & + & + & + & - & - & + & + & $\mathrm{D}$ & - & 5 \\
\hline \multicolumn{13}{|l|}{ EMRSA16 } \\
\hline t001 & $112-29$ & $\mathrm{Pn}, \mathrm{Mt}, \mathrm{Cx}, \mathrm{Er}, \mathrm{Cl}, \mathrm{Cp}, \mathrm{Km}$ & + & - & + & - & - & + & + & $\mathrm{A}$ & - & 4 \\
\hline \multicolumn{13}{|c|}{ CA-MRSA } \\
\hline t044 & $116 a / c$ & $\mathrm{Pn}, \mathrm{Mt}, \mathrm{Cx}, \mathrm{Te}, \mathrm{Fd}, \mathrm{Km}$ & - & - & + & - & - & - & + & $\mathrm{ND}$ & + & $2 \ddagger$ \\
\hline \multicolumn{13}{|l|}{ SMRSA } \\
\hline t3209 & $118 \mathrm{a} / \mathrm{d}$ & $\begin{array}{l}\text { Pn, Mt, Cx, Er, Cl, Te, Fd, } \\
\text { Km, Mp }\end{array}$ & + & - & + & - & - & + & + & A & - & 4 \\
\hline
\end{tabular}

${ }^{\star}$ Pn, Penicillin; Mt, meticillin; Cx, cefoxitin; Er, erythromycin; $\mathrm{Cl}$, clindamycin; Cp, ciprofloxacin; Te, tetracycline; $\mathrm{Gn}$, gentamicin; Fd, fusidic acid; Km, kanamycin; Mp, mupirocin.

$\dagger$ Peacock grouping refers to the combination of seven virulence genes found to be over-represented in clinical strains of MRSA (Peacock et al., 2002). ND, Not described in the original paper.

¥In addition to encoding two of the seven virulence factors, the strain also encodes the gene lukF.

cultures associated with in-patients and nasal swabs obtained from blood donors. This work showed that a subset of seven specific virulence factors were overrepresented in invasive MRSA strains.

These included adhesins that bind either fibronectin $(f n b A)$ (Jonsson et al., 1991), collagen (cna) (Patti et al., 1992) or a sialo-bone binding protein ( $s d r E$ ) (Josefsson et al., 1998; Tung et al., 2000) and three toxins that act as either a serine protease (eta) (Dancer et al., 1990), a pyrogenic toxin superantigen (sej) (Zhang et al., 1998) or a cytolysin (hlg) (Kaneko \& Kamio, 2004). The seventh virulence factor was the first gene in the ica operon that is required for efficient biofilm formation (O'Gara, 2007).

To investigate whether the carriage of these virulence factors varied between the different MRSA isolates identified during our study, we examined the carriage of the same 7 genes by the 14 individual spa types we had identified. For the 8 spa types that were found only once, we profiled the isolate available, while for the other 6 spa types, we chose one isolate as representative. In addition to the virulence factor profiling, we determined the carriage of the PVL genes, and obtained PFGE identification and antibiogram data for all 14 strains (Table 2). The results showed that 8 of the 9 EMRSA15 and both of the
EMRSA16 spa types encoded the 'D combination' of $f n b A$, cna, sdrE, hlg and ica. This combination of genes was the fourth most common in the original study, representing $10.7 \%$ of all strains. The one EMSRA15 spa type that did not match this pattern, t022, differed from the other isolates in the carriage of the $f n b A$ gene. Although rare, isolates lacking fnbA and belonging to the CC22 complex, which includes EMRSA15 strains, were reported in the original study (Peacock et al., 2002). The EMRSA3 isolate, t001, lacked the cna gene but carried the other four virulence factors found in the EMRSA 15 and EMRSA16 clusters. This 'A combination' of genes was the most common in the original study, representing $19.6 \%$ of all 334 samples, and the same profile could be assigned to the local sporadic MRSA (SMRSA) t3209. The remaining spa type, t044, lacked both $f n b A$ and cna but did encode $s d r E$ and $i c a$, the only two virulence factors to be found in all 14 strains.

Overall, our results established that 10 of the 14 samples representing the distinct spa types identified in this study carried an identical pattern of virulence factors. Therefore, while the virulence factor profiling could not discriminate between 10 of our 14 individual spa types, it did confirm the presence of a number of key virulence factors that could prove to be ideal molecules for vaccine design and anti-infective drug development. Indeed, the significance of 
SdrE as a surface antigen has already been recognized in the development of a four-component subunit vaccine that is protective in mice (Stranger-Jones et al., 2006).

\section{PFGE and antiobiogram dataset}

The PFGE identification system used by the Scottish Reference Laboratory confirmed our BURP analysis, which had clustered 11 of our 14 distinct spa types into two classes. The PFGE pattern of two single spa types also corresponded to discrete strains associated with either SMRSA or CAMRSA. The Scottish MRSA Reference Laboratory identified the remaining t001 isolate as a PFGE variant of EMRSA3 referred to as SMRSA112, a local subtype associated with Ninewells Hospital (G. Edwards, pers. comm.). We also noted that the PFGE identified four discrete band variants ( $\mathrm{a}, \mathrm{b}, \mathrm{i}$ and $\mathrm{t}$ ) within the $15 \mathrm{t} 032$ isolates analysed (data not shown). One of these PFGE band patterns (15a) was also characteristic of the $\mathrm{t} 025, \mathrm{t} 718$ and t756 spa types. The antiobiograms of the 14 different spa types were typical of those seen by the Scottish MRSA Laboratory and broadly in line with the literature, which reports a narrowing resistance pattern in epidemic strains (Amorim et al., 2007). The SMRSA t3209 had an extended resistance pattern but borderline meticillin resistance. While this is typical of the strain, its importance as a reservoir of resistance genes appears to be limited by the fact that its occurrence in Scotland is rare and declining (G. Edwards, pers. comm.).

\section{Conclusion}

To the best of our knowledge, this work represents the first comparison of MRSA strains isolated from HCWs and patients associated with the same wards during the same period of time. Importantly, we established that there was no significant difference between the strains transiently colonizing the nasal tracts of both HCWs and patients, and those causing disease. We also report that four virulence factors are common to 10 of the 14 spa types identified, supporting the idea that these are key mediators of colonization and disease.

\section{ACKNOWLEDGEMENTS}

We would like to acknowledge the support of the BMS staff in Ninewells Microbiology Department, the Scottish MRSA Reference Laboratory, and in particular Dr Giles Edwards and Dr Donald Morrison. D.H.E. would also like to thank Ian Caithness for technical support, Professor D. N. Lee and the Dean of The Medical School, Professor Brian Burchell, who supported this study. This work was supported by the Anonymous Trust (University of Dundee) and a DDS grant from the Dean's office.

\section{REFERENCES}

Amagai, M., Matsuyoshi, N., Wang, Z. H., Andl, C. \& Stanley, J. R. (2000). Toxin in bullous impetigo and staphylococcal scalded-skin syndrome targets desmoglein 1. Nat Med 6, 1275-1277.
Amorim, M. L., Faria, N. A., Oliveira, D. C., Vasconcelos, C., Cabeda, J. C., Mendes, A. C., Calado, E., Castro, A. P., Ramos, M. H. \& other authors (2007). Changes in the clonal nature and antibiotic resistance profiles of methicillin-resistant Staphylococcus aureus isolates associated with spread of the EMRSA-15 clone in a tertiary care Portuguese hospital. J Clin Microbiol 45, 2881-2888.

Bannerman, T. L., Hancock, G. A., Tenover, F. C. \& Miller, J. M. (1995). Pulsed-field gel electrophoresis as a replacement for bacteriophage typing of Staphylococcus aureus. J Clin Microbiol 33, 551-555.

Brown, E. L., Dumitrescu, O., Thomas, D., Badiou, C., Koers, E. M., Choudhury, P., Vazquez, V., Etienne, J., Lina, G. \& other authors (2009). The Panton-Valentine leukocidin vaccine protects mice against lung and skin infections caused by Staphylococcus aureus USA300. Clin Microbiol Infect 15, 156-164.

Dancer, S. J., Garratt, R., Saldanha, J., Jhoti, H. \& Evans, R. (1990). The epidermolytic toxins are serine proteases. FEBS Lett 268, 129132.

Deurenberg, R. H., Vink, C., Kalenic, S., Friedrich, A. W., Bruggeman, C. A. \& Stobberingh, E. E. (2007). The molecular evolution of methicillin-resistant Staphylococcus aureus. Clin Microbiol Infect 13, 222-235.

Elasri, M. O., Thomas, J. R., Skinner, R. A., Blevins, J. S., Beenken, K. E., Nelson, C. L. \& Smeltzer, M. S. (2002). Staphylococcus aureus collagen adhesin contributes to the pathogenesis of osteomyelitis. Bone 30, 275-280.

Enright, M. C. \& Spratt, B. G. (1999). Multilocus sequence typing. Trends Microbiol 7, 482-487.

Frenay, H. M., Bunschoten, A. E., Schouls, L. M., van Leeuwen, W. J., Vandenbroucke-Grauls, C. M., Verhoef, J. \& Mooi, F. R. (1996). Molecular typing of methicillin-resistant Staphylococcus aureus on the basis of protein A gene polymorphism. Eur J Clin Microbiol Infect Dis 15, 60-64.

Ghebremedhin, B., Konig, W., Witte, W., Hardy, K. J., Hawkey, P. M. \& Konig, B. (2007). Subtyping of ST22-MRSA-IV (Barnim epidemic MRSA strain) at a university clinic in Germany from 2002 to 2005. J Med Microbiol 56, 365-375.

Harmsen, D., Claus, H., Witte, W., Rothganger, J., Claus, H., Turnwald, D. \& Vogel, U. (2003). Typing of methicillin-resistant Staphylococcus aureus in a university hospital setting by using novel software for spa repeat determination and database management. J Clin Microbiol 41, 5442-5448.

Harmsen, D., Claus, H. \& Vogel, U. (2005). DNA sequence-based tandem repeat analysis of the $c l f B$ gene is less discriminatory than $s p a$ typing for methicillin-resistant Staphylococcus aureus. Int $\mathrm{J}$ Med Microbiol 294, 525-528.

Johnson, A. P., Aucken, H. M., Cavendish, S., Ganner, M., Wale, M. C., Warner, M., Livermore, D. M. \& Cookson, B. D. (2001). Dominance of EMRSA-15 and -16 among MRSA causing nosocomial bacteraemia in the UK: analysis of isolates from the European Antimicrobial Resistance Surveillance System (EARSS). J Antimicrob Chemother 48, 143-144.

Jonsson, K., Signas, C., Muller, H. P. \& Lindberg, M. (1991). Two different genes encode fibronectin binding proteins in Staphylococcus aureus. The complete nucleotide sequence and characterization of the second gene. Eur J Biochem 202, 1041-1048.

Josefsson, E., McCrea, K. W., Ni Eidhin, D., O'Connell, D., Cox, J., Hook, M. \& Foster, T. J. (1998). Three new members of the serineaspartate repeat protein multigene family of Staphylococcus aureus. Microbiology 144, 3387-3395.

Kaneko, J. \& Kamio, Y. (2004). Bacterial two-component and heteroheptameric pore-forming cytolytic toxins: structures, pore-forming 
mechanism, and organization of the genes. Biosci Biotechnol Biochem 68, 981-1003.

Koreen, L., Ramaswamy, S. V., Graviss, E. A., Naidich, S., Musser, J. M. \& Kreiswirth, B. N. (2004). spa typing method for discriminating among Staphylococcus aureus isolates: implications for use of a single marker to detect genetic micro- and macrovariation. J Clin Microbiol 42, 792-799.

Kuhn, G., Francioli, P. \& Blanc, D. S. (2006). Evidence for clonal evolution among highly polymorphic genes in methicillin-resistant Staphylococcus aureus. J Bacteriol 188, 169-178.

Labandeira-Rey, M., Couzon, F., Boisset, S., Brown, E. L., Bes, M., Benito, Y., Barbu, E. M., Vazquez, V., Höök, M. \& other authors (2007). Staphylococcus aureus Panton-Valentine leukocidin causes necrotizing pneumonia. Science 315, 1130-1133.

Lina, G., Piemont, Y., Godail-Gamot, F., Bes, M., Peter, M. O., Gauduchon, V., Vandenesch, F. \& Etienne, J. (1999). Involvement of Panton-Valentine leukocidin-producing Staphylococcus aureus in primary skin infections and pneumonia. Clin Infect Dis 29, 1128-1132.

MacKenzie, F. M., Greig, P., Morrison, D., Edwards, G. \& Gould, I. M. (2002). Identification and characterization of teicoplanin-intermediate Staphylococcus aureus blood culture isolates in NE Scotland. J Antimicrob Chemother 50, 689-697.

Malachowa, N., Sabat, A., Gniadkowski, M., Krzyszton-Russjan, J., Empel, J., Miedzobrodzki, J., Kosowska-Shick, K., Appelbaum, P. C. \& Hryniewicz, W. (2005). Comparison of multiple-locus variablenumber tandem-repeat analysis with pulsed-field gel electrophoresis, spa typing, and multilocus sequence typing for clonal characterization of Staphylococcus aureus isolates. J Clin Microbiol 43, 3095-3100.

Moore, P. C. \& Lindsay, J. A. (2002). Molecular characterisation of the dominant UK methicillin-resistant Staphylococcus aureus strains, EMRSA-15 and EMRSA-16. J Med Microbiol 51, 516-521.

Murchan, S., Aucken, H. M., O'Neill, G. L., Ganner, M. \& Cookson, B. D. (2004). Emergence, spread, and characterization of phage variants of epidemic methicillin-resistant Staphylococcus aureus 16 in England and Wales. J Clin Microbiol 42, 5154-5160.

Nashev, D., Toshkova, K., Salasia, S. I., Hassan, A. A., Lammler, C. \& Zschock, M. (2004). Distribution of virulence genes of Staphylococcus aureus isolated from stable nasal carriers. FEMS Microbiol Lett 233, 45-52.

O'Gara, J. P. (2007). ica and beyond: biofilm mechanisms and regulation in Staphylococcus epidermidis and Staphylococcus aureus. FEMS Microbiol Lett 270, 179-188.

Patti, J. M., Jonsson, H., Guss, B., Switalski, L. M., Wiberg, K., Lindberg, M. \& Hook, M. (1992). Molecular characterization and expression of a gene encoding a Staphylococcus aureus collagen adhesin. J Biol Chem 267, 4766-4772.

Peacock, S. J., Moore, C. E., Justice, A., Kantzanou, M., Story, L., Mackie, K., O'Neill, G. \& Day, N. P. (2002). Virulent combinations of adhesin and toxin genes in natural populations of Staphylococcus aureus. Infect Immun 70, 4987-4996.

Shopsin, B., Gomez, M., Montgomery, S. O., Smith, D. H., Waddington, M., Dodge, D. E., Bost, D. A., Riehman, M., Naidich, S. \& Kreiswirth, B. N. (1999). Evaluation of protein A gene polymorphic region DNA sequencing for typing of Staphylococcus aureus strains. J Clin Microbiol 37, 3556-3563.

Stranger-Jones, Y. K., Bae, T. \& Schneewind, O. (2006). Vaccine assembly from surface proteins of Staphylococcus aureus. Proc Natl Acad Sci U S A 103, 16942-16947.

Tung, H., Guss, B., Hellman, U., Persson, L., Rubin, K. \& Ryden, C. (2000). A bone sialoprotein-binding protein from Staphylococcus aureus: a member of the staphylococcal Sdr family. Biochem J 345, 611-619.

Zhang, S., landolo, J. J. \& Stewart, G. C. (1998). The enterotoxin D plasmid of Staphylococcus aureus encodes a second enterotoxin determinant (sej). FEMS Microbiol Lett 168, 227-233. 